$\underline{\text { Original Article }}$

\title{
Impact of Pretransplant Donor and Recipient Cytomegalovirus Serostatus on Outcome for Multiple Myeloma Patients Undergoing Reduced Intensity Conditioning Allogeneic Stem Cell Transplantation
}

Jean El-Cheikh ${ }^{1,2}$, Raynier Devillier ${ }^{1,2}$, Roberto Crocchiolo ${ }^{1,2}$, Sabine Fürst ${ }^{1,2}$, Boris Calmels ${ }^{3}$, Catherine Faucher ${ }^{1,2}$, Anne Marie Stoppa ${ }^{2}$, Angela Granata ${ }^{1,2}$, Luca Castagna ${ }^{1,2}$, Patrick Ladaique ${ }^{3}$, Claude Lemarie ${ }^{3}$, Reda Bouabdallah ${ }^{2}$, Christine Zandotti ${ }^{4}$, Michele Merlin ${ }^{5}$, Pierre Berger ${ }^{5}$, Christian Chabannon ${ }^{3}$ and Didier Blaise ${ }^{1,2}$.

${ }^{1}$ Unité de Transplantation et de Thérapie Cellulaire (U2T), Institut Paoli-Calmettes, Marseille, France.

${ }^{2}$ Département d'Onco-Hématologie, Institut Paoli-Calmettes, Marseille, France.

${ }^{3}$ Centre de Thérapie Cellulaire, Institut Paoli-Calmettes, Marseille, France.

${ }^{4}$ Département de Microbiologie, Institut Paoli-Calmettes, Marseille, France.

${ }^{5}$ Service de Virologie, Hôpital de la Timone, Marseille, France.

Correspondence to: Jean El Cheikh, M.D. Unité de Transplantation et de Thérapie Cellulaire (U2T), Institut PaoliCalmettes, 232 Boulevard Ste Marguerite, 13009 Marseille Cedex 09, France. Tel: +33 491 223823; Fax: +33 491 223579. E-Mail: elcheikhj@ipc.unicancer.fr

Competing interests: The authors have declared that no competing interests exist.

Published: April 10, 2013

Received: February 25, 2013

Accepted: March 26, 2013

Citation: Mediterr J Hematol Infect Dis 2013, 5(1): e2013026, DOI: 10.4084/MJHID.2013.026

This article is available from: http://www.mjhid.org/article/view/11556

This is an Open Access article distributed under the terms of the Creative Commons Attribution License (http://creativecommons.org/licenses/by/2.0), which permits unrestricted use, distribution, and reproduction in any medium, provided the original work is properly cited.

Abstract. Scope of the study was to investigate the impact of pre-transplant CMV serostatus of the donor and/or recipient on the outcome of patients undergoing allogeneic hematopoietic stem cell transplantation (Allo-SCT) for Multiple Myeloma (MM). To our knowledge no data are available in the literature about this issue.

We retrospectively followed 99 consecutive patients who underwent reduced-intensity conditioning (RIC) Allo-SCT for MM in our cancer center at Marseille between January 2000 and January 2012. Based upon CMV serostatus, patients were classified as low risk (donor [D]-/recipient [R]-) 17 patients $(17.1 \%)$, intermediate risk $(D+/ R) 14$ patients $(14.1 \%)$, or high risk - either (D-/R+) 31 patients $(31.3 \%)$ or $(\mathrm{D}+/ \mathrm{R}+), 37$ patients $(37.3 \%)$.

Cumulative incidence of CMV reactivation was $39 \%$ with a median time of 61 days (26-318). Three patients (3\%) developed CMV disease. Two factors were associated with CMV reactivation: CMV serostatus group (low: $0 \%$ vs. intermediate: $29 \%$ vs. high: $50 \% ; p=0.001$ ) and the presence of grade II-IV acute GvHD (Hazard Ratio: HR=2.1 [1.1-3.9]). Thirty-six of the 39 patients (92\%) with CMV reactivation did not present positive detection of CMV after a 21-day median duration preemptive treatment with ganciclovir. Cumulative incidence of day 100 grade II-IV acute GvHD, 1-year chronic GvHD and day 100 transplantation related mortality (TRM) were $37 \%, 36 \%$ and 9\%, respectively. CMV reactivation and serostatus were not associated with increased GvHD and TRM 
or short survival. Only the presence of acute GvHD as a time dependent variable was significantly associated with increased TRM $(\mathbf{p}=\mathbf{0 . 0 0 5})$. Two-year overall and progression free survival were $56 \%$ and $34 \%$, respectively.

Donor and recipient CMV serostatus and acute GvHD are independent factors for increased CMV reactivation in high-risk MM patients undergoing RIC Allo-SCT. However, we did not find any influence of CMV reactivation on post transplantation outcome. CMV monitoring and pre-emptive treatment strategy could in part explain these results. Novel prophylactic measures such as immunotherapy and drug prophylaxis need to be considered in this group of patients, warranting further prospective studies.

Introduction. The introduction of allogeneic hematopoietic stem cell transplantation (Allo-SCT), and novel anti-myeloma agents such as bortezomib, thalidomide and lenalidomide has improved the outcome of patients with multiple myeloma (MM) who relapse or are refractory to standard therapies. ${ }^{1,2}$ AlloSCT at present is considered in the first-line therapy of $\mathrm{MM}$ only in young high-risk patients ${ }^{1}$. These advances have transformed myeloma into a chronic condition, with multiple relapses, salvage therapies and chronic immunodeficient states leading to high infection rates. Human cytomegalovirus (CMV) infection remains one of the major complications after Allo-SCT and is associated with considerable morbidity and mortality. ${ }^{3,4}$ The incidence of CMV infection increases with the intensity and duration of immunosuppression and occurs in roughly $70 \%$ of patients after Allo-SCT, depending on both donor and recipient serostatus. ${ }^{5,6}$ Without antiviral intervention, about $50 \%$ of patients with culture-proven CMV infection will develop CMV disease. Despite the use of antiviral prophylaxis and pre-emptive antiviral therapy, CMV diseases continue to be reported in 15 to $25 \%$ of patients. ${ }^{7-9}$ Frequent clinical manifestations of CMV disease are interstitial pneumonitis, gastrointestinal (GI) disease and hepatitis; retinitis, encephalitis and marrow suppression have also been described. The present approach to managing CMV disorders consists of peripheral blood monitoring using either CMV pp65 antigen (antigenemia assay) or polymerase chain reaction (PCR). ${ }^{10,11}$

Pre-emptive therapy with either ganciclovir or foscarnet is initiated in patients detected as positive. Factors identified for CMV reactivation are CMV seropositive status of the donor, type of conditioning regimen, use of T-cell depletion, and graft-versus-host disease (GvHD). ${ }^{12,13}$ With the introduction of newer conditioning regimens including reduced-intensity conditioning (RIC) Allo-SCT and the increased use of in vivo T-cell depleting agents such as anti-thymocyte globulin (ATG) and monoclonal antibodies such as alemtuzumab (anti-CD52), it has become essential to determine whether a specific high-risk subgroup can be identified. $^{14,15}$ These patients could benefit from more intensive or innovative prophylactic strategies as opposed to a general pre-emptive strategy. To our knowledge no data are available in the literature about this issue. We have attempted to study CMV reactivation patterns in 99 consecutive patients with MM who underwent RIC Allo-SCT in our cancer centre at Marseille, where serial CMV monitoring has been done, to ascertain the risks of CMV reactivation.

Patients and Methods. This is a retrospective analysis of MM patients who underwent RIC Allo-SCT at our centre between January 2000 and January 2012. The data were collected from the transplant database and individual medical records. A total of 99 patients (median age 53 years, range 27-67) underwent RIC Allo-SCT, including 59 males and 40 females. Ninetysix patients $(97 \%)$ received one or more prior autologous transplantations (Auto-SCT). Twenty-seven patients $(27 \%)$ were transplanted as the first line treatment strategy whereas 72 patients $(73 \%)$ had received other treatments. Those 27 patients were considered for Allo-SCT because they had poor prognostic factors like cytogenetic aberrations (Del (13q14), and/or Del 17 and/or t (4; 14)) or they didn't have at least partial remission (PR) after Auto-SCT. The median time between Auto-SCT and Allo-SCT was 19 months (1-89). The disease status at time of transplantation was Complete Remission (CR) or VGPR in $22 \%$, PR or stable disease (SD) in $67 \%$, and progression or refractory disease (PD) in $11 \%$. Patient characteristics are shown in Table 1.

Seventy-three patients $(74 \%)$ had matched related donors (MRD) and 26 patients (26\%) had unrelated donors (URD). Eighteen patients (18\%) had an HLAallelically matched URD, a so-called 10/10 match, and 8 patients (8\%) had 9/10 HLA-matched antigens (four of them had a DQ allele mismatch, two patients had a $\mathrm{Cw}$ mismatch and two had A mismatch). The graft source was peripheral blood stem cells (PBSC) in 88 patients $(89 \%)$, bone marrow in nine patients $(9 \%)$, and cord blood in two (2\%). T-cell depletion with ATG was used in 68 patients $(69 \%)$ and low-grade total body irradiation (TBI) with 2 Gys was used in 30 recipients $(31 \%)$ of RIC transplants, respectively. 
Table 1. Patient and transplantation characteristics

\begin{tabular}{|c|c|}
\hline Patient and transplantation characteristics & $\mathrm{n}=99(\%)$ \\
\hline Patients Age (median) [range] & 53 years [27-67] \\
\hline Male gender & $59(60)$ \\
\hline \multicolumn{2}{|l|}{ Myeloma-subtype } \\
\hline $\mathrm{IgG}$ & $52(53)$ \\
\hline $\operatorname{IgA}$ & $23(23)$ \\
\hline Light Chain & $12(12)$ \\
\hline Bence jones & $8(8)$ \\
\hline Other & $4(4)$ \\
\hline \multicolumn{2}{|l|}{ Cytogenetics at diagnosis } \\
\hline Normal & $14(14)$ \\
\hline $\operatorname{Del}(13)$ or $\operatorname{Del}(17)$ or $t(4 ; 14)$ & $24(24)$ \\
\hline NA & $61(62)$ \\
\hline Median number of prior chemotherapies before Allo-SCT [range] & $2[1-5]$ \\
\hline 1 line & $27(27)$ \\
\hline 2 lines & $46(47)$ \\
\hline 3 lines & $15(15)$ \\
\hline$>3$ lines & $11(11)$ \\
\hline Median number of prior Auto-SCT [range] & $2[1-4]$ \\
\hline 1 & $57(58)$ \\
\hline 2 & $31(31)$ \\
\hline$>2$ & $8(8)$ \\
\hline \multicolumn{2}{|l|}{ Status of Myeloma at Allo-SCT } \\
\hline $\mathrm{CR}$ & $12(12)$ \\
\hline VGPR & $10(10)$ \\
\hline $\mathrm{PR} / \mathrm{SD}$ & $66(67)$ \\
\hline $\mathrm{PD}$ & $11(11)$ \\
\hline Median interval between Auto- and Allo-SCT months [range] & 19 [1-89] \\
\hline \multicolumn{2}{|l|}{ Donor type } \\
\hline MRD & $73(74)$ \\
\hline URD & $26(26)$ \\
\hline Donor/recipient sex mismatch & $48(48)$ \\
\hline \multicolumn{2}{|l|}{$\mathrm{ABO}$ compatibility } \\
\hline Yes & $63(64)$ \\
\hline No & $36(36)$ \\
\hline \multicolumn{2}{|l|}{ Donor/recipient CMV serostatus } \\
\hline D-/R- (low risk) & $17(17)$ \\
\hline $\mathrm{D}+/ \mathrm{R}-$ (intermediate risk) & $14(14)$ \\
\hline $\mathrm{D}+/ \mathrm{R}+($ high risk $)$ & $31(31)$ \\
\hline $\mathrm{D}-/ \mathrm{R}+$ (high risk) & $37(37)$ \\
\hline Donor Median age years (range) & $46(20-71)$ \\
\hline \multicolumn{2}{|l|}{ Conditioning regimen } \\
\hline $\mathrm{Flu}+\mathrm{Bu}+\mathrm{ATG}$ & $68(69)$ \\
\hline Flu + TBI & $25(25)$ \\
\hline Other RIC & $6(6)$ \\
\hline \multicolumn{2}{|l|}{ GvHD prophylaxis } \\
\hline CSA & $56(57)$ \\
\hline $\mathrm{CSA}+\mathrm{MMF}$ & $41(41)$ \\
\hline MMF & $2(2)$ \\
\hline \multicolumn{2}{|l|}{ Stem cell source } \\
\hline Peripheral Blood & $88(89)$ \\
\hline Bone Marrow & $9(9)$ \\
\hline Cord blood & $2(2)$ \\
\hline \multicolumn{2}{|l|}{ Stem cell dose median [range] } \\
\hline CD34+ x 106/kg & $5.41[0.16-12.8]$ \\
\hline $\mathrm{CD} 3+\mathrm{x} 106 / \mathrm{kg}$ & $299[5-745]$ \\
\hline
\end{tabular}

Legend: CR, complete remission; VGPR, very good partial remission; PR, partial remission, PD, progressive disease; Flu, fludarabine; Bu, busulfan; ATG, antithymocyte globulin; CR, complete remission; VGPR, very good partial remission; PR, partial remission, PD, progressive disease; MRD, matched related donor; URD, unrelated donor; GVHD, graft versus host disease; CSA, cyclosporine A; MMF, mycophenolate mofetyl.

GvHD prophylaxis consisted of cyclosporine A in 56 patients (57\%), CSA + mycophenolate mofetyl (MMF) in 41 patients $(41 \%)$ and MMF alone in two patients (2\%). Transplant characteristics are shown in Table 2.
Based upon previous exposure to CMV, patients were classified into low risk (donor and recipient negative; D-/R-), intermediate risk (donor positive with recipient negative; $\mathrm{D}+/ \mathrm{R}-$ ), or high risk (recipient 
All patients $(\mathrm{n}=99)$

$39 \%$

CMV serostatus

$$
\begin{aligned}
& \text { Low risk }(\mathrm{n}=17) \\
& \text { Intermediate risk }(\mathrm{n}=14) \\
& \text { High risk }(\mathrm{n}=68)
\end{aligned}
$$

Time from diagnosis to allo-SCT

$$
\begin{aligned}
& <=24 \text { months }(\mathrm{n}=45) \\
& >24 \text { months }(\mathrm{n}=54)
\end{aligned}
$$

Disease status at allo-SCT

$$
\text { CR or VGPR ( } \mathrm{n}=23)
$$

Previous treatment lines

$$
1 \text { line }(\mathrm{n}=27)
$$

Donor type*

$$
\begin{aligned}
& \operatorname{MRD}(\mathrm{n}=72) \\
& \operatorname{URD}(\mathrm{n}=24)
\end{aligned}
$$

Graft source*

$$
\begin{aligned}
& \text { PBSC }(n=88) \\
& \text { Bone marrow }(n=8)
\end{aligned}
$$

Transplantation period

$$
<2006(\mathrm{n}=42)
$$

Conditioning regimen with ATG

$$
\begin{aligned}
& \text { Yes }(\mathrm{n}=68) \\
& \text { No }(\mathrm{n}=31)
\end{aligned}
$$

CMV detection method

$$
\begin{aligned}
& \operatorname{pp} 65(n=65) \\
& \operatorname{PCR}(n=34)
\end{aligned}
$$

Acute GVHD $\$$

" Patients with allo-SCT from cord blood $(\mathrm{n}=2)$ and haploidentical donor $(\mathrm{n}=1)$ were excluded of this analysis. ${ }^{\$}$ The occurrence of GVHD was analyzed as a time dependent variable

positive with donor either negative [D-/ R+] or positive $[\mathrm{D}+/ \mathrm{R}+])$. Seventeen patients $(17 \%)$ were $\mathrm{D}-/ \mathrm{R}-, 14$ patients $(14 \%)$ were $\mathrm{D}+/ \mathrm{R}-, 31$ patients $(31 \%)$ were $\mathrm{D}-$ $/ \mathrm{R}+$ and 37 patients $(37 \%)$ were $\mathrm{D}+\mathrm{R}+$.

Supportive care. Our protocol in providing supportive care was the same throughout this time period. Prophylactic treatment against pneumocystis jirovecii and toxoplasmosis consisted of trimethoprimsulfamethoxazole $(10 \mathrm{mg} / \mathrm{Kg} /$ day $)$ administered twice weekly. Patients also received daily oral amoxicillin (500 mg x 3/day) as prophylaxis against encapsulated bacteria and prophylaxis against herpes simplex virus including oral valacyclovir (500 mg x $2 /$ day). Patients were monitored for CMV reactivation during the first 12 months after transplant, and pre-emptive therapy with ganciclovir was given if CMV reactivation occurred.

CMV monitoring and treatment. Serial weekly monitoring for CMV quantification was done using either pp65 antigen (between 2000 and 2009) or a quantitative PCR assay (COBAS R, Roche Diagnostics, Branchburg, New Jersey, USA) (from 2009 to the present). Monitoring was performed weekly initially, starting from transplantation until day 90 , and then every 4-8 weeks during the next six months. If there was evidence of reactivation (pp65 >2 cells $/ 200,000$ or PCR $>1000$ copies $/ \mathrm{mL}$ ), treatment was started with ganciclovir $(5 \mathrm{mg} / \mathrm{kg}$ IV twice daily) for 2 weeks, provided two consecutive PCRs done three days apart became negative. If the PCR was still 
positive after 2 weeks of treatment, a maintenance therapy with ganciclovir $(5 \mathrm{mg} / \mathrm{kg}$ IV once /day) for another 14 days was proposed. CMV disease was diagnosed on demonstration of tissue invasion in biopsy specimens or demonstration of a positive CMV early antigen on bronchoalveolar lavage, along with clinical and radiological features consistent with CMV. Statistics. Data are presented as medians, ranges, and 95\% confidence intervals (CI). The end points analysed were overall survival (OS), progression free survival (PFS), transplant related mortality (TRM) and acute and chronic GvHD. OS was defined as the time elapsed from Allo-SCT to death, whatever the cause of death. PFS was defined as survival with no evidence of relapse or progression. Kaplan-Meier product-limit estimates were used to assess the probabilities of OS and PFS. ${ }^{16}$ The Prentice estimate and Gray test, allowing the consideration of competing events, were used to calculate the cumulative incidences of GvHD, relapse, CMV reactivation and TRM. ${ }^{17,18}$

Cox regression was used to find any association between major pre-transplant variables and OS or $\mathrm{PFS} ;{ }^{19}$ the occurrence of CMV reactivation, acute GvHD and chronic GvHD were all considered as timedependent covariates. If two or more variables were associated with $\mathrm{p}<0.20$ to each endpoint of interest, then a multivariate model was constructed. SPSS v13.0 and R 2.12.2 were used for the above cited analyses (http://www.R-project.org).

Results. CMV reactivation, disease and treatment. The cumulative incidence of CMV reactivation was 39\% $(n=39)$ with a median time of 61 [26-318] days after Allo-SCT. Twenty-three patients $(59 \%)$ were under corticosteroid treatment for GvHD. There was no difference in the median time (days) of reactivation based upon its method of detection using pp65 (54 [32162]) or quantitative PCR (65[34-162]). The incidence of CMV reactivation at $1,3,6$ and 12 months after Allo-SCT was 30\%, 35\%, 37\% and 39\%, respectively (Figure 1). Three patients (3\%) developed CMV disease (two pneumonitis and one disseminated GI and lung disease) at a median of 38 days (26-49) post AlloSCT. There was no difference in the median time to reactivation based on donor type (MRD versus URD; 48 versus 46 days), graft source - bone marrow (45 days) versus PBSC (47 days) versus cord blood (46 days) - the year of transplant (before or after 2006), the use of ATG in the conditioning regimen, the age of the donor (more or less than 50 years) or the presence of chronic GvHD.

By univariate analysis, CMV reactivation was significantly influenced by CMV serostatus risk group (high: $50 \%$ vs intermediate: $29 \%$ vs low: $0 \%$; $\mathrm{p}=0.001$; Table 2 and Figure 1). In the high-risk group

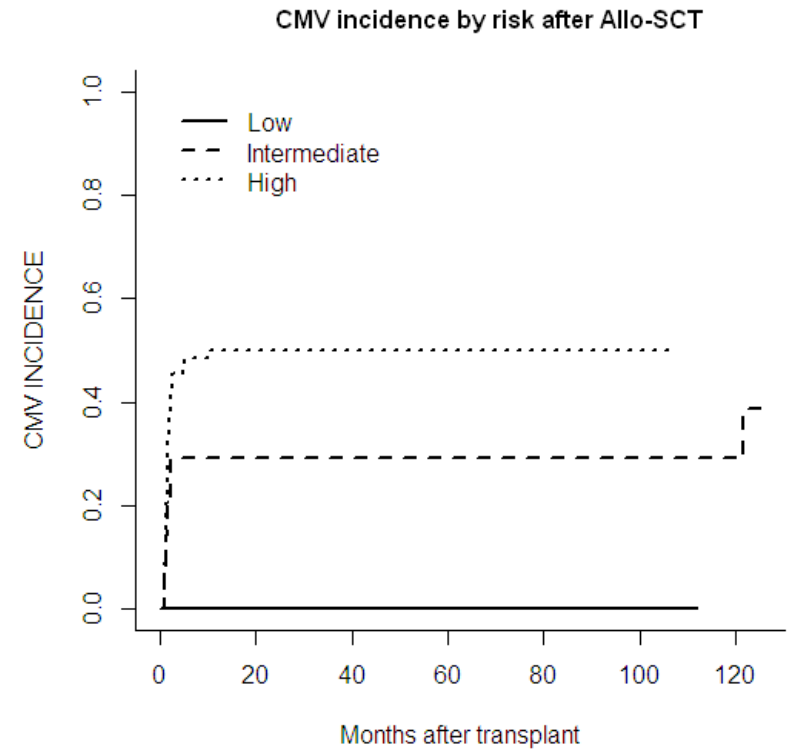

Figure1. CMV incidence by risk after Allo-SCT

characterised by a positive CMV serostatus recipient, the serostatus of the donor (positive vs. negative) did not influence CMV reactivation. The presence of acute GvHD as a time-dependent variable was associated with an increased cumulative incidence of CMV reactivation $(\mathrm{p}=0.032)$. Donor type, disease stage, recipient and donor ages, female-to-male graft, graft source (bone marrow versus PBSC versus cord blood), time of transplant (pre- or post-2006), the disease status, the number of lines of previous therapy and time from diagnosis to transplant, the death for other causes, the relapse of the underlying disease, or the presence of chronic GvHD, use of the new anti-myeloma drugs, use of ATG during conditioning and corticosteroid therapy did not significantly influence the incidence of CMV reactivation. Details of the results are shown in

\section{Tables 2 and 4.}

By multivariate analysis, CMV reactivation was associated with CMV serostatus (HR: 3.8 [1.6-2.9], $\mathrm{p}=0.002$ ) and the presence of acute GvHD (HR: 2.5 [1.3-4.9], $\mathrm{p}=0.006$ ).

All 39 patients with CMV reactivation received ganciclovir. Resolution of CMV viremia occurred in 36 patients (92\%) after a median of 21 days (range 7-64). Of the three patients who did not have resolution of viremia, all had extensive chronic GvHD. Two of them died of CMV disease while one patient died of disease progression. Recurrent reactivations (after resolution of the first episode with antiviral therapy) were seen in 15 patients, predominantly in patients with chronic GvHD. Outcome after Allo-SCT. The median 2-year OS and PFS were $56 \%$ and $34 \%$, respectively.

Cumulative incidences of day-100 grade II-IV acute GvHD, 2-year chronic GvHD and 2-year 
extensive chronic GvHD were $37 \%, 36 \%$ and $29 \%$, respectively. The median TRM at 100 days and one year was $9 \%$ and $21 \%$, respectively. All the 10 analyzable pathogenic microorganisms are classified in the table 3 by descending order of frequency.

Table 3. Classification of pathogenic microorganisms recovered from bloodstream in patients with infection related mortality.

\begin{tabular}{|l|c|}
\hline Microorganism & $\begin{array}{c}\text { No. }(\%) \\
\text { Of isolates } \\
(\mathbf{n = 1 0})\end{array}$ \\
\hline Virus & $\mathbf{5 ( 5 \% )}$ \\
CMV & 2 \\
Epstein bar Virus & 1 \\
HHV6+ herpes virus & 1 \\
BK virus & 1 \\
\hline Gram-positive cocci $\quad$ Staphylococcus haemolyticus & $\mathbf{1}(\mathbf{1 \% )}$ \\
- $\quad 1$ \\
\hline Gram-negative rods $\quad$ Escherichia coli & $\mathbf{3 ( 3 \% )}$ \\
- Pseudomonas & 2 \\
- $\quad 1$ \\
\hline Yeasts & $\mathbf{1 ( 1 \% )}$ \\
Aspergillus fumigatus & $\mathbf{1}$ \\
\hline
\end{tabular}

No impact of pretransplant CMV serostatus on engraftment occurred in any patients. Causes of death were relatively similar between the two groups except for deaths that occurred due to CMV in the group that had reactivation. There was no increase in mortality related to bacterial or other viral infections in patients with CMV reactivation. By univariate analysis, CMV serostatus (low risk versus intermediate risk versus high risk) had no impact on the OS (Figure 2).

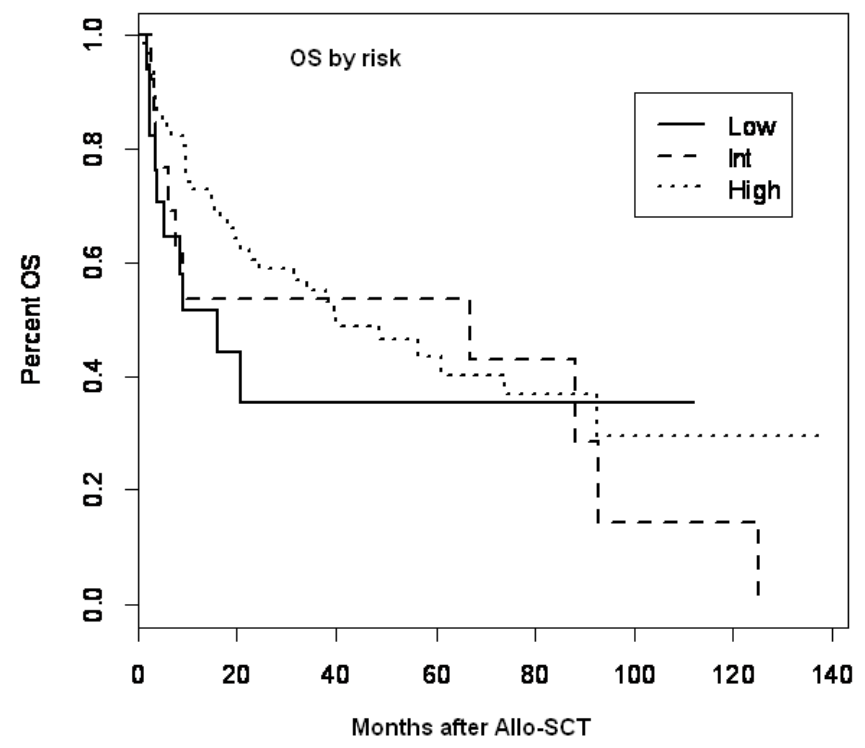

Figure 2. Overall survival (OS) by risk

Other factors, although evaluated, such as donor type (MRD vs. URD), disease stage, patient and donor ages, female-to-male graft, graft source (bone marrow versus PBSC versus cord blood, time of transplant (before or after 2006), use of the new anti-myeloma drugs, use of ATG during conditioning and corticosteroid therapy did not significantly influence OS, PFS or TRM. CMV reactivation analysed as a time dependent variable did not influence OS (HR=1.4 [0.82.4]) (Table 4). Only the presence of acute GvHD as a time dependent variable was significantly associated with increased TRM ( $p=0.005)$ (Table 4).

Discussion. Infections in patients with MM represent a clinical challenge. The list of potential pathogens is long and changes over the disease course. ${ }^{20}$ The aim of this study was to discern the effects of pre-transplant CMV serostatus on the outcome of Allo-SCT in MM patients. To the best of our knowledge, this is the first and largest study reporting on the role of CMV serostatus prior to RIC Allo-SCT in MM patients.

CMV infection remains a major problem following Allo-SCT and different groups have adopted different treatment strategies to reduce the morbidity and mortality related to CMV. One strategy was to serially monitor patients in post Allo-SCT for CMV and start pre-emptive therapy with ganciclovir or foscarnet once there was evidence of reactivation. ${ }^{6,82}$ This practice was established in our institution in 2000, and analysis of this pre-emptive strategy suggests that a third of our patients (39\%) develop reactivation. Most importantly, the reactivations occurred in the high-risk groups (D$/ \mathrm{R}+$ or $\mathrm{D}+/ \mathrm{R}+$ ), suggesting pre-transplant recipient seropositivity is perhaps the most important risk factor for reactivation. ${ }^{5,5,22}$ This study showed no impact of pre-transplant CMV serostatus on engraftment in the three risk groups. Previous studies suggested that the CMV serostatus of patients was important not only in terms of reactivation but also in terms of worsening TRM and reducing OS. ${ }^{5,22}$ However, in our study, we did not observe worse outcomes in the high-risk group as compared with the other groups. Moreover, we did not find any correlation between CMV reactivation and poor outcome. Interestingly grade II-IV acute GvHD was associated with a higher incidence of CMV infection and there was no increase in mortality related to bacterial or other viral infections in patients with CMV reactivation. In addition to the immunodeficiency related to myeloma and its complications, the type of anti-myeloma therapy used also plays a role in the development of infection, but in this study we did not find an impact of the new antimyeloma drugs on the outcome of patients after AlloSCT in any of the three risk groups. These therapeutic strategies impact differently on the immune system, predisposing patients to various opportunistic infections. ${ }^{20,23}$ A cumulative suppression of cellmediated immunity is particular to MM, and results from the combined effect of repetitive use of high-dose corticosteroids, the chronic nature of the disease with 
Table 4. Transplantation outcome

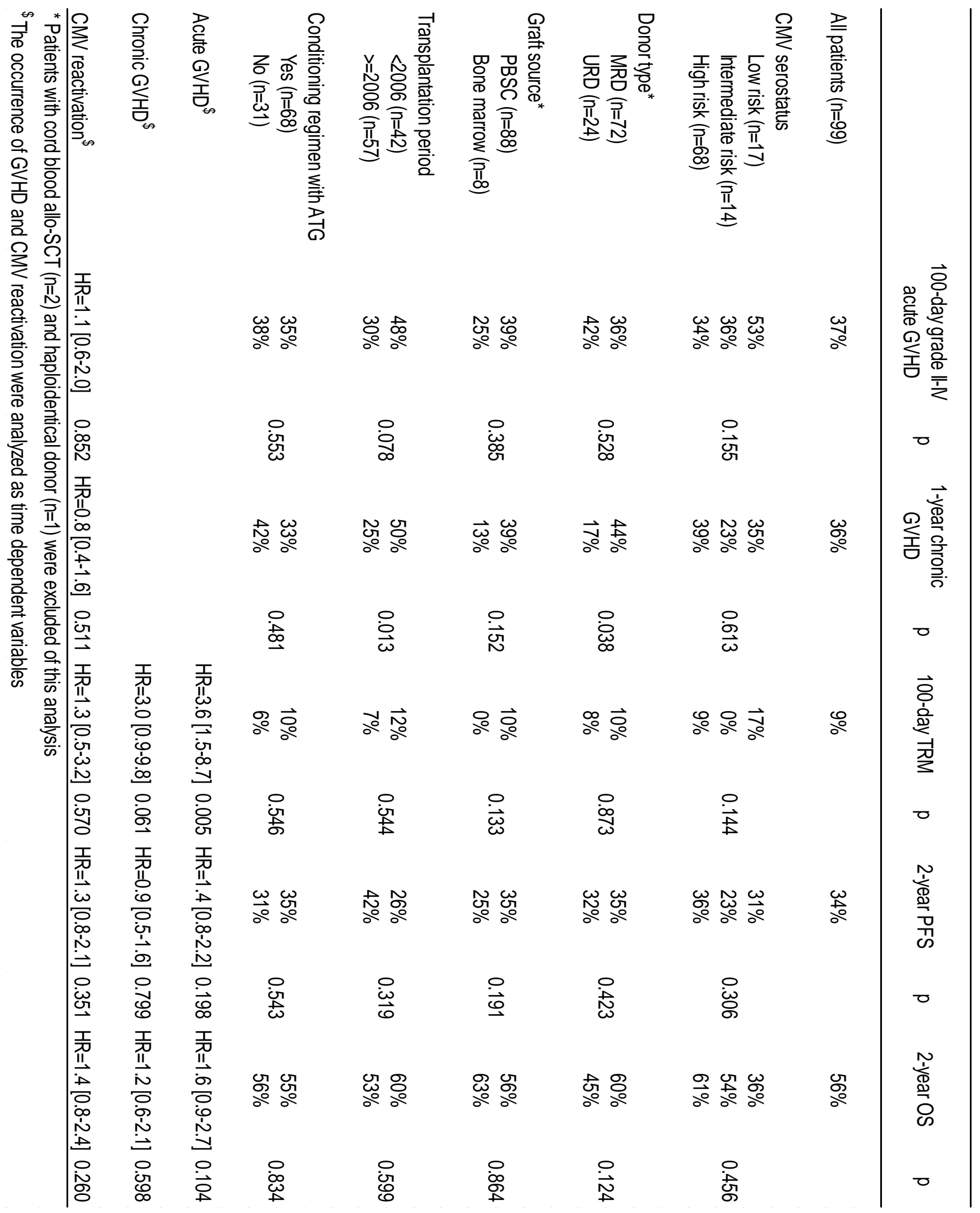


multiple relapses requiring salvage therapies (almost always containing dexamethasone), and the addition of bortezomib, a powerful immunosuppressive agent or other immunomodulatory agents like thalidomide and lenalidomide in different treatment phases. ${ }^{20,24,25}$ In addition, all patients treated with bortezomibcontaining regimens should receive prophylaxis for HSV and VZV infection. ${ }^{26,27}$ Recently, as reported by our group, the introduction of these novel agents was associated with an improved outcome and we did not observe an increased incidence of infectious disease in patients with high risk MM treated with RIC AlloSCT. ${ }^{28}$ Initial data on RIC transplants seemed to suggest the incidence of CMV infections with RIC is no different from Myeloablative transplantation (MAT) though the onset of CMV disease seemed to be later. ${ }^{11,15}$ More recent data suggest there is a higher incidence of CMV reactivation with RIC transplants, more so with the addition of anti-T-cell antibodies to the conditioning regimen. ${ }^{29-31}$ The use of MMF for GvHD prophylaxis was also not found to be associated with an increased risk of CMV reactivation, in contrast with limited published data available from both marrow and solid organ transplants that seem to suggest an increased risk with the use of MMF, ${ }^{6,32}$ probably because the patients who had received MMF in our study did not receive ATG in the conditioning regimens. Similarly, the use of a URD and the type of graft source did not seem to impact on CMV reactivation. In a study comparing patients undergoing non-MAT from URD with MRD, the incidence of CMV reactivation was slightly higher with URD, though the difference was not statistically significant. ${ }^{33}$ It is possible that the higher number of RIC Allo-SCT done using MRD (47\%) rather than URD (26.7\%) may have negated the effect of URD on CMV reactivation. Ljungman et al, in a very large study from the EBMT megafile, reported there was a strong influence of donor CMV serostatus on outcome in URD transplantations. ${ }^{34}$ Patients receiving grafts from CMVseropositive URD had improved OS and EFS and reduced TRM. However, Walker et al, in a large study involving 753 patients, showed that the graft source (cord blood versus PBSC versus bone marrow) did not independently contribute to CMV reactivation and that patient serostatus was the major determinant of reactivation. ${ }^{35}$ The EBMT study could find no effect of donor CMV serostatus on the risk of acute GvHD. ${ }^{34}$ But analyses of donor CMV serostatus on the risk of chronic GvHD gave different results. Recently, at our institution, we did not observe a higher incidence of infections in MM patients who received transplants from URD compared to patients with MRD. ${ }^{36}$
Furthermore, in this study we observed that grade IIIV acute GvHD was associated with a higher incidence of CMV infection and disease. Unlike the EBMT study, our results indicate that only acute GvHD was a unique factor associated with a higher risk of CMV reactivation. This higher risk was found to be independent of the use of URD or the use of ATG in the conditioning regimens. The incidence of CMV disease was $3 \%$ and was limited to the high-risk group alone $(\mathrm{D}+/ \mathrm{R}+$ and $\mathrm{D}-/ \mathrm{R}+)$.

In conclusion, our findings of comparable outcomes in the three CMV risk groups for MM patients prepared with RIC regimens are important because they suggest that CMV pre-transplant serostatus and reactivation has no influence on OS, PFS and TRM. However, novel prophylactic measures such as immunotherapy and drug prophylaxis need to be considered in this specific group of patients after acute GvHD, warranting further prospective studies.

Funding. We would like to thank the Association pour la Recherche sur le Cancer (ARC) (Pole ARECA) for their generous support of our research. Our group was supported by several grants from the French Ministry of Health as part of the Programme Hospitalier de Recherche Clinique (PHRC).

Transparency Declaration. No conflicts of interest to declare.

Author contributions: Jean El-Cheikh conceived and designed the study, collected and analysed data, performed statistical analyses, provided clinical care, and wrote and revised the manuscript; Raynier Devillier and Roberto Crocchiolo collected and analysed data, performed statistical analyses, provided clinical care and revised the manuscript. Sabine Furst, Catherine Faucher, Claire Oudin, Angela Granata, Luca Castagna, Anne Marie Stoppa and Reda Bouabdallah provided clinical care and commented on the manuscript.

Pierre Berger and Christine Zandotti performed microbiologic and virologic monitoring and controls and commented on the manuscript. Christian Chabannon, Patrick Ladaique, Boris Calmels and Claude Le Marie are in charge of the cell therapy facility that collected and delivered allogeneic the blood cell grafts infused into patients included in this analysis, and commented on the manuscript. Didier Blaise recruited patients, provided clinical care and commented on the manuscript.

Acknowledgments. We thank the nursing staff for providing excellent care for our patients and the 
physicians of the Hematology Department at the Institut Paoli-Calmettes for their important study

\section{References:}

1. Crawley C, Lalancette M, Szydlo R, Gilleece M, Peggs K, Mackinnon $\mathrm{S}$ et al. Outcomes for reduced-intensity allogeneic transplantation for multiple myeloma: an analysis of prognostic factors from the Chronic Leukaemia Working Party of the EBMT. Blood 2005; 105: 4532-4539. http://dx.doi.org/10.1182/blood2004-06-2387 PMid:15731182

2. Kumar SK, Rajkumar SV, Dispenzieri A, Lacy MQ, Hayman SR, Buadi FK et al. Improved survival in multiple myeloma and the impact of novel therapies. Blood 2008; 111: 2516-2520. http://dx.doi.org/10.1182/blood-2007-10-116129 PMid:17975015 PMCid:2254544

3. Bacigalupo A, Tedone E, Sanna MA, Moro F, Van Lint MT, Grazi $\mathrm{G}$ et al. CMV infections following allogeneic BMT: risk factors, early treatment and correlation with transplant related mortality. Haematologica 1992; 77: 507-513. PMid:1337746

4. Ljungman P. CMV infections after hematopoietic stem cell transplantation. Bone Marrow Transplant 2008; 42 Suppl 1: S70S72. http://dx.doi.org/10.1038/bmt.2008.120 PMid:18724309

5. Boeckh M, Nichols WG. The impact of cytomegalovirus serostatus of donor and recipient before hematopoietic stem cell transplantation in the era of antiviral prophylaxis and preemptive therapy. Blood 2004; 103: 2003-2008. http://dx.doi.org/10.1182/blood-2003-10-3616 PMid:14644993

6. George B, Pati N, Gilroy N, Ratnamohan M, Huang G, Kerridge I et al. Pre-transplant cytomegalovirus (CMV) serostatus remains the most important determinant of CMV reactivation after allogeneic hematopoietic stem cell transplantation in the era of surveillance and preemptive therapy. Transpl. Infect Dis 2010; 12: 322-329. http://dx.doi.org/10.1111/j.1399-3062.2010.00504.x PMid:20487414

7. Verma A, Devine S, Morrow M, Chen YH, Mihalov M, Peace D et al. Low incidence of CMV viremia and disease after allogeneic peripheral blood stem cell transplantation. Role of pretransplant ganciclovir and post-transplant acyclovir. Bone Marrow Transplant 2003; 31: 813-816. http://dx.doi.org/10.1038/sj.bmt.1703916 PMid: 12732890

8. Ljungman P, Reusser P, de la Camara R, Einsele H, Engelhard D, Ribaud P et al. Management of CMV infections: recommendations from the infectious diseases working party of the EBMT. Bone Marrow Transplant 2004; 33: 1075-1081. http://dx.doi.org/10.1038/sj.bmt.1704505 PMid:15077131

9. Zaia JA, Schmidt GM, Chao NJ, Rizk NW, Nademanee AP, Niland JC et al. Preemptive ganciclovir administration based solely on asymptomatic pulmonary cytomegalovirus infection in allogeneic bone marrow transplant recipients: long-term follow-up. Biol Blood Marrow Transplant 1995; 1: 88-93. PMid:9118297

10. Nitsche A, Oswald O, Steuer N, Schetelig J, Radonic A, Thulke S et al. Quantitative real-time PCR compared with pp65 antigen detection for cytomegalovirus (CMV) in 1122 blood specimens from 77 patients after allogeneic stem cell transplantation: which test better predicts CMV disease development? Clin Chem 2003; 49: $\quad 1683-1685 . \quad$ http://dx.doi.org/10.1373/49.10.1683 PMid:14500600

11. Schetelig J, Oswald O, Steuer N, Radonic A, Thulke S, Held TK et al. Cytomegalovirus infections in allogeneic stem cell recipients after reduced-intensity or myeloablative conditioning assessed by quantitative PCR and pp65-antigenemia. Bone Marrow Transplant 2003; 32: 695-701. http://dx.doi.org/10.1038/sj.bmt.1704164 PMid:13130317

12. Ljungman P, Perez-Bercoff L, Jonsson J, Avetisyan G, Sparrelid E, Aschan $J$ et al. Risk factors for the development of cytomegalovirus disease after allogeneic stem cell transplantation. Haematologica 2006; 91: 78-83. PMid:16434374

13. Miller W, Flynn P, McCullough J, Balfour HH, Jr., Goldman A, Haake $\mathrm{R}$ et al. Cytomegalovirus infection after bone marrow transplantation: an association with acute graft-v-host disease. Blood 1986; 67: 1162-1167. PMid:3006831

14. Chakrabarti S, Mackinnon S, Chopra R, Kottaridis PD, Peggs K, $\mathrm{O}^{\prime}$ Gorman $\mathrm{P}$ et al. High incidence of cytomegalovirus infection contributions and dedicated patient care.

after nonmyeloablative stem cell transplantation: potential role of Campath-1H in delaying immune reconstitution. Blood 2002; 99 : 4357-4363. PMid:12036862

15. Hill QA, Hill A, Collyns TA, Pearce RM, Cook G. Similar lymphocyte recovery and CMV reactivation profiles between reduced intensity conditioning with alemtuzumab and myeloablative allogeneic stem cell transplantation. Bone Marrow Transplant $\quad 2008$; $\quad 41$ : $449-751$ http://dx.doi.org/10.1038/sj.bmt.1705974 PMid:18195685

16. Kaplan EL, Meier P. Nonparametric estimation from incomplete observations. J Am Stat Assoc 1958; 53: 457-481. http://dx.doi.org/10.1080/01621459.1958.10501452

17. Fine J. A proportional hazards model for the subdistribution of a competing risk. J Am Stat Assoc 1999; 94: 496-509. http://dx.doi.org/10.1080/01621459.1999.10474144

18. Gooley TA, Leisenring W, Crowley J, Storer BE. Estimation of failure probabilities in the presence of competing risks: new representations of old estimators. Stat. Med 1999; 18: 695-706. http://dx.doi.org/10.1002/(SICI)10970258(19990330)18:6<695::AID-SIM60>3.0.CO;2-O

19. Cox DR. Regression models and life tables. Journal of the Royal Statistical Society: Serie B (Methodological) 1972; 34: 187-220.

20. Nucci M, Anaissie E. Infections in patients with multiple myeloma in the era of high-dose therapy and novel agents. Clin Infect Dis 2009; 49: 1211-1225. http://dx.doi.org/10.1086/605664 PMid:19769539

21. Ljungman P. Molecular monitoring of viral infections after hematopoietic stem cell transplantation. Int J Hematol 2010; 91 596-601. http://dx.doi.org/10.1007/s12185-010-0570-4 PMid:20414752

22. Nichols WG, Corey L, Gooley T, Davis C, Boeckh M. High risk of death due to bacterial and fungal infection among cytomegalovirus (CMV)-seronegative recipients of stem cell transplants from seropositive donors: evidence for indirect effects of primary CMV infection. J Infect Dis 2002; 185: 273-282. http://dx.doi.org/10.1086/338624 PMid:11807708

23. Haslett PA, Hanekom WA, Muller G, Kaplan G. Thalidomide and a thalidomide analogue drug costimulate virus-specific CD8+ T cells in vitro. J Infect Dis 2003; 187: 946-955. http://dx.doi.org/10.1086/368126 PMid:12660941

24. Weber DM, Chen C, Niesvizky R, Wang M, Belch A, Stadtmauer EA et al. Lenalidomide plus dexamethasone for relapsed multiple myeloma in North America. N Engl J Med 2007; 357: 2133-2142. http://dx.doi.org/10.1056/NEJMoa070596 PMid:18032763

25. Schutt P, Brandhorst D, Stellberg W, Poser M, Ebeling P, Muller $\mathrm{S}$ et al. Immune parameters in multiple myeloma patients: influence of treatment and correlation with opportunistic infections Leuk Lymphoma 2006; 47: 1570-1582. http://dx.doi.org/10.1080/10428190500472503 PMid:23469683 PMCid:3610087

26. Mitsiades CS, Davies FE, Laubach JP, Joshua D, San MJ, Anderson $\mathrm{KC}$ et al. Future directions of next-generation novel therapies, combination approaches, and the development of personalized medicine in myeloma. J Clin Oncol 2011; 29: 1916 $1923 . \quad$ http://dx.doi.org/10.1200/JCO.2010.34.0760 PMid:21482978

27. Laubach JP, Mahindra A, Mitsiades CS, Schlossman RL, Munshi $\mathrm{NC}$, Ghobrial IM et al. The use of novel agents in the treatment of relapsed and refractory multiple myeloma. Leukemia 2009; 23: 2222-2232. PMid:19741729 PMCid:31 $\underline{\text { http://dx }}$

28. El-Cheikh J, Crocchiolo R, Boher JM, Furst S, Stoppa AM, Faucher $\mathrm{C}$ et al. Allogeneic transplant for myeloma in the era of new drugs: have the outcomes improved? Leuk Lymphoma 2012; 53: 1630-1632. http://dx.doi.org/10.3109/10428194.2012.656630 PMid:23469683 PMCid:3610087

29. Chakrabarti S. Increased CMV infection following nonmyeloablative allogeneic stem cell transplantation: a search for 
the guilty. Blood 2003; 101: 2071. http://dx.doi.org/10.1182/blood2002-11-3598 PMid:12584145

30. George B, Kerridge I, Gilroy N, Huang G, Hertzberg M, Gottlieb D et al. Fludarabine-based reduced intensity conditioning transplants have a higher incidence of cytomegalovirus reactivation compared with myeloablative transplants. Bone Marrow Transplant 2010; 45: 849-855. http://dx.doi.org/10.1038/bmt.2009.273 PMid:19915635

31. Nivison-Smith I, Dodds AJ, Doocey R, Ganly P, Gibson J, Ma DD et al. Allogeneic hematopoietic cell transplant for multiple myeloma using reduced intensity conditioning therapy, 1998-2006: factors associated with improved survival outcome. Leuk Lymphoma $\quad 2011 ; \quad 52: \quad 1727-1735$. http://dx.doi.org/10.3109/10428194.2011.582201

PMid:23469683 PMCid:3610087

32. Hambach L, Stadler M, Dammann E, Ganser A, Hertenstein B. Increased risk of complicated CMV infection with the use of mycophenolate mofetil in allogeneic stem cell transplantation. Bone Marrow Transplant 2002; 29: 903-906. http://dx.doi.org/10.1038/sj.bmt.1703583 PMid:12080355

33. Junghanss C, Storb R, Maris MB, Carter RA, Sandmaier BM, Maloney DG et al. Impact of unrelated donor status on the incidence and outcome of cytomegalovirus infections after nonmyeloablative allogeneic stem cell transplantation. Br J Haematol 2003; 123: 662-670. $\quad$ http://dx.doi.org/10.1046/j.1365 2141.2003.04671.x PMid:14616970

34. Ljungman P, Brand R, Einsele H, Frassoni F, Niederwieser D, Cordonnier C. Donor CMV serologic status and outcome of CMVseropositive recipients after unrelated donor stem cell transplantation: an EBMT megafile analysis. Blood 2003; 102: 4255-4260. $\quad$ http://dx.doi.org/10.1182/blood-2002-10-3263 PMid:12933590

35. Walker CM, van Burik JA, De For TE, Weisdorf DJ Cytomegalovirus infection after allogeneic transplantation: comparison of cord blood with peripheral blood and marrow graft sources. Biol Blood Marrow Transplant 2007; 13: 1106-1115. http://dx.doi.org/10.1016/j.bbmt.2007.06.006 PMid:17697973

36. El-Cheikh J, Crocchiolo R, Boher JM, Furst S, Stoppa AM, Ladaique $\mathrm{P}$ et al. Comparable outcomes between Unrelated and Related donors after Reduced Intensity Conditioning Allogeneic hematopoietic Stem Cell Transplantation in patients with high risk Multiple Myeloma. Eur. J Haematol 2012. http://dx.doi.org/10.1111/j.1600-0609.2012.01777.x PMid:22385049 